International Journal of Zoological Investigations

Contents available at Journals Home Page: www.ijzi.net

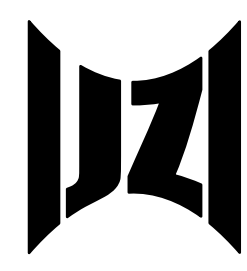

ISSN: 2454-3055

\title{
Hydrovatus Motschulsky with Description of a New Species (Coleoptera: Dytiscidae: Hydroporinae) from Southern India
}

\author{
Senthil Kumar G. ${ }^{*}$, Kalaimagal P. ${ }^{2}$ and Issaque Madani J. ${ }^{3}$ \\ 1PG and Research Department of Zoology, Thiru Kolanjiappar Government Arts College, Vriddhachalam-606 001, Tamil Nadu, \\ India \\ 2 Department of Zoology, Joseph Arts and Science College, Thirunavalur- 607 204, Tamil Nadu, India \\ 3PG and Research Department of Zoology, The New College, Chennai-600 014, Tamil Nadu, India \\ *Corresponding Author
}

Received: $6^{\text {th }}$ October, 2020

Accepted: $9^{\text {th }}$ November, 2020

Published online: $11^{\text {th }}$ November, 2020

https://doi.org/10.33745/ijzi.2020.v06i02.013

\begin{abstract}
A new species Hydrovatus vaziranii n.sp. in the genus Hydrovatus Motschulsky (Dytiscidae: Hydroporinae) is described from south India. A key is provided to the seven species of the genus Hydrovatus belonging to the confertus group along with eighteen species currently known from India based on the morphological characters.
\end{abstract}

Keywords: Coleoptera, Dytiscidae, Hydrovatus, Apomorphy, Synapomorphy, Plesiomorphous

Citation: Senthil Kumar G., Kalaimagal P. and Issaque Madani J.: Hydrovatus Motschulsky with description of a new species (Coleoptera: Dytiscidae: Hydroporinae) from Southern India. Intern. J. Zool. Invest. 6 (2): 338-342, 2020. https://doi.org/10.33745/ijzi.2020.v06i02.013

\section{Introduction}

Hydrovatus Motschulsky is a species-rich genus with members occurring throughout southern India, Asia. A Catalogue prepared by Nilsson (2013) in which 205 species occupied the delimitation of zoogeographical regions as applied in the Afrotropical, Australian, Nearctic, Neotropical, Oriental, Pacific and Palearctic. The genus Hydrovatus belonging to the confertus group along with eighteen species in which seven species are discussed now. Sharp (1882) includes the two genera Hydrovatus and Queda Sharp. Wolfe (1988) proposed unification Methlini and Hydrovatus, on the basis of some morphological similarities. Régimbart (1895), Guignot (1945, 1959) and Omer-Cooper (1957) have worked on the various species of Hydrovatus from Africa and Madagascar, Franciscolo (1979) 
and Zaitzev (1972) dealt with the fauna of Europe and Palearctis, Régimbart (1899) and Vazirani (1970) dealt with the species from Oriental region. The Australian species were described by Watts (1978). Young (1956, 1963) discussed the fauna of America.

Biström (1996) has provided a complete taxonomic survey of Hydrovatus with diagnoses and descriptions of all recognized taxa and keys for the identification of adults. In this study, a new species Hydrovatus vaziranii n.sp. in the genus Hydrovatus Motschulsky (Dytiscidae: Hydroporinae) is described from south India.

\section{Materials and Methods}

The aquatic adephagan beetles Hydrovatus were collected from ponds near Kancheepuram. The D-Frame net (300 mm x $400 \mathrm{~mm} \times 330 \mathrm{~mm}$ ) with a mesh size of 0.5 $\mathrm{mm}$ was used for collection. The collected water beetles were preserved in 70\% alcohol. Observations were made with $\mathrm{Zm} 45 \mathrm{TM}$ complete zoom stereo trinocular microscope. The abdomen was carefully detached and placed in a warm solution of $10 \% \mathrm{KOH}$ for about $10 \mathrm{~min}$ and washed in distilled water before dissection. The male genitalia (penis and parameres) were mounted on a card along with the insect in euparol. To make illustrations camera lucida was used. The genitalia were preserved in small vials together with the specimen in 70\% alcohol as suggested by Biström (1996).

ZSI : Zoological Survey of India, Chennai. Z.S.I. Regd. No. : I/CL/7 dated 24.5.2006

\section{Results}

Key to the species of Hydrovatus - confertus group from India:

1. Male with stridulation apparatus.
Male without stridulation apparatus. H. vaziranii sp.n.

2. Antenna of male modified .......................

Antenna of male not modified ...............3

3. Punctation on elytra quite dense.....H. pinguis Régimbart

Punctation on elytra sparse. H. sinister Sharp

4. Male antenna with segments 4-11 not equally broad .............. 5

Male antenna with segments 4-11 equally broad.............................. stridulus Biström

5. Stridulatory files consist of 18-22 strongly built, elevated ridges....... subtilis Sharp

Stridulatory files consist of many minute discernable ridges.

$6.5^{\text {th }}-7^{\text {th }}$ antennal segments enlarge. H. confertus Sharp

$4^{\text {th }}-6^{\text {th }}$ antennal segments enlarged. ..H. obtusus Motschulsky

\section{New species}

Hydrovatus vaziranii Kumar, Kalaimagal and Madani, new species

Type locality: India, Tamil Nadu, Kancheepuram, Orikkai, 76 Km N Chennai.

Material examined: Holotype: $\widehat{1} 1$ ex. (ZSI) ; Allotype: $q 1$ ex. ; Paratypes: 5 ex. ; India: Tamil Nadu, Kancheepuram District, Orikkai

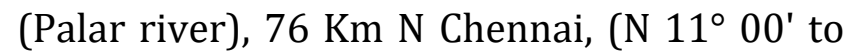
$12^{\circ} 00^{\prime}$ latitudes and $77^{\circ} 28^{\prime}$ to $78^{\circ} 50^{\prime}$ longitudes) 13. xi. 2004, 6 ex.; Kilambi, 28. x. 2012, 2 ex. ; Oragadam, 27. viii. 2013, 5 ex.

Diagnosis: Hydrovatus vaziranii is closely related to $H$. subtilis in the antennal modification, dense punctation on pronotum and elytra. It differs from $H$. subtilis in the absence of stridulatory apparatus; H. subtilis shows antennal segments 4-11 enlarged and $7^{\text {th }}$ segment somewhat expanded; in the new species $H$. vaziranii the antennal segments 3 11 are enlarged, 4 and 5 are expanded; the apex of penis is hammer shaped in the lateral aspect. 
Description: Length (TL): $2.5-2.9 \mathrm{~mm}$, breadth: 1.5-1.9 mm. Form elongate-oval, narrow, not enlarged in the middle of elytra, apex acuminate.

Head: Rufo-ferruginous, clypeus feebly raised anteriorly, rebordered and sub-straight; the distance between the eyes not exceeding $2 \frac{1}{2}$ times of the maximum width of one eye; maxillary palpus and antenna ferruginous; maxillary palpus not modified; antennal segments of 3-11 enlarged, 4 and 5 segments extremely enlarged; punctuation fine and sparse, punctures separated 3-4 times of their own diameter, a series of punctures along the inner margin of eyes; reticulation fine with distinct hexagonal meshes (Fig. 1).

Pronotum: Rufo-ferruginous, anteriorly little narrower, antero-lateral angles of the pronotum slightly produced with pointed edges bearing 3 spines; transverse row of punctation along the anterior margin and also a transverse row of large setiferous punctures along the anterior margin; reticulation distinct with hexagonal meshes (Fig. 2).

Elytra: Rufo-ferruginous, without markings, sub-marginal striae from the sub-base to apex, medially intermittent, lateral marginal stria from apex to middle provided with a row of long cilia; punctation fine and double in which large ones are sparse and small ones dense separated by their own diameter, a longitudinal row of punctures along the sutural margin; reticulation as similar to head and pronotum; apices acuminate (Fig. 3).

Ventral side: Ferruginous, stridulatory apparatus absent; punctation on meso and metasternum deep; $1^{\text {st }}$ and $2^{\text {nd }}$ abdominal sternites with a row of small hairs.
Male genitalia: Penis narrowed towards the crochet apex (Fig. 4); parameres broader proximally and narrow towards the apex, well-sclerotized apical hook bent downwards and apically with cilia (Fig. 5).

Legs: Proleg ferruginous, coxa more or less sub-rounded; trochanter small, sub-triangular with 6 setae; femur long and slender, dorsally a row of tiny spines; tibia long and slender, distally dilated, spurs equal; first three tarsal segments weakly dilated with suckers, a pair of equal claws (Fig. 6).

Mesoleg: ferruginous, coxa somewhat subrounded; trochanter sub-triangular; femur long and slender; tibia long and slender, distally dilated; first three tarsal segments dilated, ventrally with suckers, claws equal (Fig. 7).

Hind leg: ferruginous, coxa wide and flattened; trochanter triangular, smooth; femur long and slender, strongly built and flattened, dorsal and ventral sides smooth; tibia long and slender, distally more or less dilated, tibial spur single; tarsal segments more or less equal in length, claws equal (Fig. 8).

Etymology: This species is respectfully dedicated to Dr. T.G. Vazirani a pioneer aquatic Coleopterist from India.

Habitat: This species was collected in small river line steams, river lets, lakes, ponds mostly in shallow, stagnant shore parts.

Distributions: India, Tamil Nadu, Kancheepuram, Orikkai, Oragadam.

\section{Discussion}

The antenna of males of Hydrovatus shows much variation. In Hydrovatus a number of species have unmodified and slender 

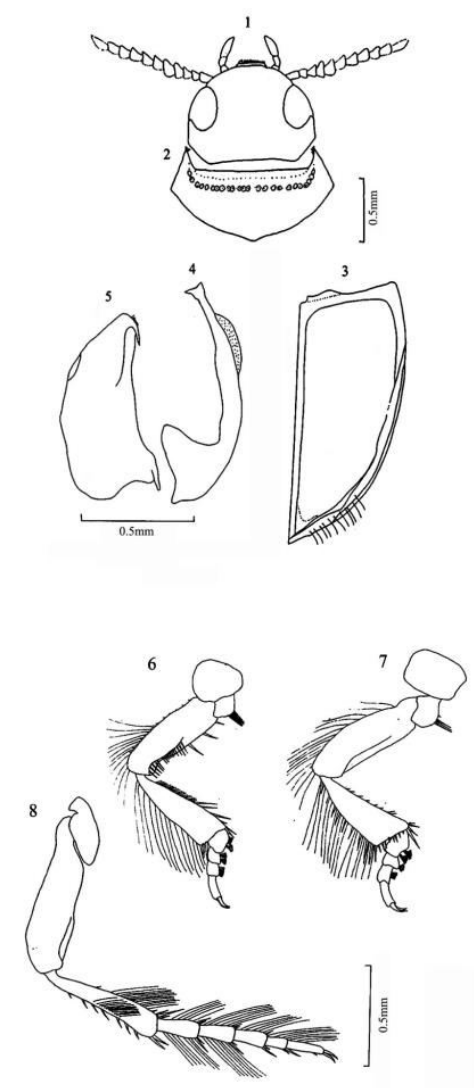

Figs. 1-8: Hydrovatus vaziranii sp. nov. (Holotype- $\widehat{\jmath}$ ); 1 --head; 2--pronotum; 3--elytra; 4--penis - lateral aspect; 5-- paramere - lateral aspect.; 6-- posterior face of proleg; 7-mesoleg; 8 -- hindleg.

antennae but many species are with a variable number of enlarged and modified antennal segments. However the female antenna is always slender and unmodified. Antennal modifications are observed in Hydrovatus, Queda and Laccornis species (Wolfe and Spangler, 1985; Wolfe and Roughley, 1990). In Hydrovatus the modified antenna appears to be scattered among the various species groups. Biström also considered that the presence of modified antenna is an apomorphy (derived state). H. vaziranii sp.nov is having the male antenna which is modified and it shares the derived character along with other species (synapomorphy).

Biström (1996) is of the view that in Hydrovatus males the protarsal claws often exhibit modifications in length, thickness and shape of claws are unequal. But, in H. vaziranii sp.nov. the male protarsal claws are equal and simple. This character is perhaps a plesiomorphous (primitive) state.

Haired penis is showing a scattered distribution in Hydradephagans. In $H$. acuminatus the penis is haired, which is an apomorphous state. In H. vaziranii sp.nov. the penis is nude, unlike $H$. acuminatus. Biström (1996) is of the opinion that this character of penis has evolved separately in different lineages in Dytiscidae.

The appearance of penis in $H$. vaziranii sp.nov. clearly indicates that the opinion of Biström (1996) can be accepted. An apically 
strongly bent penis is observed in $H$. vaziranii sp. nov., as found in many Hydrovatus species. This character is considered to be an apomorphous state. The observations on the specimens collected strongly indicate that it deserves to be assigned a new species.

\section{Acknowledgement}

The authors are grateful to the management of The New College, Chennai-14, India, for providing the space and encouragement to carry out the present work. The help rendered by Dr. G. Thirumalai, Scientist-E, Joint director and Officer-in-Charge, Southern Regional Station, Zoological Survey of India, Chennai28 , is acknowledged sincerely with thanks for his constant encouragement and critical analysis of the work.

\section{References}

Biström O. (1996) Taxonomic revision of the genus Hydrovatus Motschulsky (Coleoptera: Dytiscidae). Entomol. Basil. 19 : 57 - 584.

Franciscolo ME. (1979) Coleoptera, Haliplidae, Hygrobiidae, Gyrinidae, Dytiscidae. Fauna Itlaic. 14 : 1-804.

Guignot F. (1945) Coleoptera Dytiscidae. 2. Mission Scientifique de l'omo. Mém. Nat. Hist. Nat. 19: 215-322.

Guignot F. (1959) Revision des Hydrocanthares d' Afrique (Coleoptera: Dytiscidae) Premiere et deuxieme Parties. Ann. Mus. Congo. Belge (sr. 8. Sci. Zool.) 70: 1-316.

Nilsson AN. (2013) A World catalogue of the family Dytiscidae, or diving beetles. (Coleoptera, Adephaga) pp. 1 - 304. Version 1.I.2013.

Omer-Cooper J. (1957) Dytiscidae (Coleoptera) collected in the Transvaal. Mem. Entomol. Soc. S. Afr. $5: 1-90$.
Régimbart M. (1895) Dytiscides trouvés dans les Tabacs par les soins de M. Antoine Grouvelle. Ann. Soc. Entomol. Fr. 64 : 321 - 348.

Régimbart M. (1899) Revision des Dytiscidae de la région Indo-Sino-Malaise. Ann. Soc. Entomol. France $68: 186-367$.

Sharp D. (1882) On aquatic carnivorous Coleoptera or Dytiscidae. Sci. Trans. Roy. Dublin Soc. 2 : 179-974.

Vazirani TG. (1970) A review of Hydroporinae: Dytiscidae in part, from India. Contributions to the study of aquatic beetles (Coleoptera). 5. Oriental Ins. $4: 93-129$.

Watts CHS. (1978) The larvae of Australian Dytiscidae (Coleoptera). Austral. J. Zool. (suppl. Ser.) 57 : 1-166.

Wolfe GW. (1988) A phylogenetic investigation of Hydrovatus, Methlini and other plesiotypic hydroporines (Coleoptera: Dytiscidae). Psyche 95 : 327-344.

Wolfe GW and Roughley RE. (1990) A taxonomic, phylogenetic and zoogeographic analysis of Laccornis Gozis (Coleoptera: Dytiscidae) with the description of Laccornini, a new tribe of Hydroporinae. Quaest. Entomol. 26 : 273-354.

Wolfe GW and Spangler PJ. (1985) A synopsis of the Laccornis difformis species group with a revised key to north American species of Laccornis Des Gozis (Coleoptera: Dytiscidae). Proc. Biol. Soc. Wash. 98 : 61-71.

Young FN. (1956) A preliminary key to the species of Hydrovatus of the eastern United States (Coleoptera: Dytiscidae). Col. Bull. 10 : 53-54.

Young FN. (1963) Two new north American species of Hydrovatus with notes on other species (Coleoptera: Dytiscidae). Psyche 70 : 184-192.

Zaitzev FA. (1972) Families Amphizoidae, Hygrobiidae, Haliplidae, Dytiscidae, Gyrinidae, Coleoptera. 4. Fauna USSR 58 : 1-401. 